\title{
Applying ABC system for calculating cost price of hospital services case study: Beheshti hospital of Hamadan
}

\author{
Fariborz Niasti $^{\mathrm{a}}$, Ali Akbar Fazaeli ${ }^{\mathrm{b}, *}$, Yadollah Hamidi ${ }^{\mathrm{c}}$, Amir Viaynchi $^{\mathrm{d}}$ \\ ${ }^{a}$ Performance Monitoring and Budgeting Center, Hamadan University of Medical Sciences, Hamadan, Iran \\ ${ }^{\mathrm{b}}$ Social Determinants of Health Research Center, Hamadan University of Medical Sciences, Hamadan, Iran \\ ${ }^{\mathrm{c}}$ Department of Health Management and Economic, School of Public Health and Research Center for Health Sciences, Hamadan University of Medical Sciences, Hamadan, \\ Iran \\ ${ }^{\mathrm{d}}$ Pharmacoeconomy \& Administrative Pharmacy, School of Pharmacy, Hamadan University of Medical Sciences, Hamadan, Iran
}

\section{A R T I C L E I N F O}

\section{Keywords:}

Financial management

Hospital

Health Care Economics and Organizations

\begin{abstract}
A B S T R A C T
Introduction: activity based costing $(\mathrm{ABC})$ is an accounting method that allows organizations such as hospitals to determine costs based on the resources they consume. This method is a new and more effective cost system. In this study, ABC method was used for calculating cost price of radiology services in Beheshti hospital of Hamadan. Method: This cross-sectional study was performed in 2015. The statistical population was the diagnostic imaging department of Beheshti hospital in Hamadan University of medical sciences. The required data was collected through information forms, and the price was calculated by using Activity-Based Costing model. To apply ABC method, the hospital was divided into several cost centers and five cost categories were defined: wage, equipment, space, material, and overhead costs. Then activity centers were defined.

Results: the highest costs were for human resources $(65.2 \%)$ and the lowest ones for energy conduits costs (0.4\%). According to the obtained results the total cost of the support sector in Beheshti Hospital during the study period was 64,091,093,852 IRR.

Conclusion: By utilizing $\mathrm{ABC}$, hospital managers have a valuable accounting system that provides a true insight into the organizational costs of their department. The results of this study indicated that there are differences between the real price of radiology services and approved tariffs. Suggest until tariff amending, hospital commence to modify financial and personnel structures and repair its costs.
\end{abstract}

\section{Introduction}

Over the recent decades, the increased healthcare costs resulting from technology development on the one hand and enhanced level of health awareness and expectations on the other hand have induced problems in financing healthcare services. ${ }^{1}$ The health sector is facing severe resource constraints in many countries. In this regard, managers in healthcare sector shall consider achieving maximum efficiency as an integral part of the healthcare system management. ${ }^{2}$ A major portion of the health sector resources is allocated to hospitals. ${ }^{3}$ Thus, evaluating financial performance and calculating the total cost of services provided in this sector facilitate appropriate and favorable planning to increase efficiency and productivity. Diagnostic services provided by the hospital wards account for a major part of the costs. ${ }^{4}$ Among the most important data and financial information required for a manager in diagnostic wards is the costs allocated to cost units and service unit costs. ${ }^{5}$ Calculation of the total cost of services can improve managers' performance in terms of budgeting, strategic planning, outsourcing, transfers, and privatization as well as their overall organizational performance. ${ }^{6}$ Using the activity-based costing method also will allow hospital managers to determine their pricing policies and to make more accurate decisions on budgeting and strategy planning. ${ }^{2,7}$ Very few studies have been performed on the economics of hospitals in middleincome countries. Most of the studies have focused on individual units of hospital such as application of $\mathrm{ABC}$ in calculating cost price of surgery services. ${ }^{8,9}$ Considering legal requirements and ultimate goals ${ }^{10}$ of operational budgeting and final price calculations in adopting right decisions about the allocation of public resources based on measurable outcomes to create a rational process for decision-making, planning, evaluation and reporting performance relying on the activity-based costing technique, the total cost of all services provided by a relative value unit (called K) of Imaging Department of Beheshti Education and Treatment Center in Hamadan was calculated and compared with the approved tariffs in 2015.

\footnotetext{
* Corresponding author.

E-mail address: afazaeli83@gmail.com (A.A. Fazaeli).
} 


\section{Method}

\subsection{Data collection}

The present study was an applied descriptive study conducted in 2015. In order to estimate the radiology services costs in Beheshti Hospital, the ABC technique was used. Data was extracted using field studies through identifying cost centers and pre-specified tables. The study population and sample similarly consisted of the diagnostic imaging ward of Beheshti Hospital in Hamadan.

\subsection{Data management and analysis}

To run the $\mathrm{ABC}$ technique, the following steps were adopted ${ }^{11}$ :

Step 1 . The activity centers of the hospital were identified. They impose direct costs on the activity centers and attract indirect costs from other activity centers. ${ }^{12}$

Step 2. The identified activity centers were classified into three categories in terms of operations

i. Operational centers

ii. Diagnostic centers

iii. Public support activity centers such as accounting or logistic units, etc. ${ }^{13}$

Step 3. The output (activity) was determined for the imaging ward. A list of activities and the relative value of the relevant activity was determined using a book entitled 'relative values'. Then, the levels of activity in specific quarter periods were reported from the Hospital Information System (HIS).

Step 4. Examining the documents available in this step, the details of all expenditures were extracted based on personnel costs (salary, fee, clothes payments, management payments, etc), materials used for public consumption, specific materials and requirements, consumed drugs, energy costs, depreciation (building and equipment) and the like.

Step 5. The cost of each activity center was assigned to the total cost centers. Regarding their origins, the costs were divided into 2 groups (i) Costs that are created in an activity center; (ii) Costs imposed by other activity centers to an activity center (overhead costs). ${ }^{14}$ The total costs of administrative, support and radiology activity centers of Beheshti Hospital were separately calculated for 3-month intervals in 2015.

Step 6. The total cost per output unit was determined. After identifying the costs related to final pools of activity centers or centers possessing output to calculate the total cost of each output, the total costs allocated to each activity center was divided by the number of defined outputs for each activity center and the cost per output was obtained.To determine the exact cost of each service provided by the radiology activity center based on the portion of each service in total services offered in a 3- month interval, total relative value of the services (K) was estimated using 'relative value of a service' and divided by total value allocated to each activity center and the total price $(\mathrm{K})$ was obtained. Total price was also achieved multiplying (K) by 'relative value for a service'.

Step 7. Services cost-benefit was estimated for the radiology ward of Beheshti Hospital during 3-month intervals in 2015 by comparing the total cost and the tariffs determined by the Ministry of Health, Treatment and Medical Education.

Step 8. The contribution of various costs (personnel, materials and consumed goods, medicines and equipment, etc.) was calculated for (K) to predict and estimate the financial impact of different policies on the total cost. ${ }^{15}$

To calculate the equipment depreciation costs, some information was obtained about medical equipment available in the hospital and then a list of available equipment and detailed information about the purchase date and price and its power consumption were extracted from activity centers by matching the list and the list available in each activity center. ${ }^{16}$

Since the hospital building does not belong to the university, the monthly rental fee and the cost of repairs carried out during this period were considered as depreciation cost of the hospital building. Then, the share of activity centers was calculated with regard to the hospital foundation area. The required statistical data related to radiology ward costs including salaries and job bonuses, available equipment in the radiology ward, consumed goods and supplies received from storeroom, consumed equipment and tools, the cost of water, electricity, gas, phone, fax, and internet subscription services were separately tabulated for activity centers. The required information was collected referring to the accounting unit, revenue and discharge accounting unit, medical records unit, storerooms, public and administrative affairs offices, medical equipment unit, information and technology unit, outpatient wards, human resources unit, and nursing office through reviewing available documents and receiving payroll system reports, energy consumption control and monitoring system, HIS system, Ghasedak system and new financial system.

\section{Results}

Hospital imaging department has $3.2 \%$ of the total number of the hospital expert, technical, and service human resources $(\mathrm{N}=21)$ at its disposal and provides imaging services. According to Table 1 and with regard to the hospital physical resources, the costs for separate activity centers were determined. From 19000 square meters foundation area, 614 square meters $(3.2 \%)$ is allocated to the imaging department.

The findings associated with the consumed energy conduits costs in hospitals show that, of the total costs of energy conduits consumptions and phone amounted to $2,584,812,535$ IRR, $16.1 \%$ and $3.4 \%$ are allocated to support and imaging sectors, respectively; see Table (2).

As shown in Table 3, the frequency of services provided in the imaging sector was 41362. In this regard, the highest and the lowest

Table 1

Beheshti Hospital area specified for costs of activity centers.

\begin{tabular}{|c|c|c|c|c|}
\hline department/unit & \multicolumn{2}{|l|}{ Wards } & Foundation $\left(\mathrm{m}^{2}\right)$ & Foundation (\%) \\
\hline Imaging Department & \multicolumn{2}{|c|}{ CT scan, ultrasonography, bone densitometry and radiology } & 614 & 3.2 \\
\hline \multirow[t]{8}{*}{ Support Units } & Administrative and financi & & 420 & 2.2 \\
\hline & Storeroom & & 136 & 0.7 \\
\hline & Service and Support Units & Installation & 1618 & 12.3 \\
\hline & & kitchen & 358 & \\
\hline & & Laundry & 242 & \\
\hline & & Waste elimination & 99 & \\
\hline & & Guarding & 26 & \\
\hline & & Transportation & 9 & \\
\hline Hospital & & & 19000 & 16.50 \\
\hline
\end{tabular}


Table 2

Cost of the consumed energy conduits for support wards in Beheshti Hospital (IRR).

\begin{tabular}{|c|c|c|c|c|c|c|}
\hline Unit & Water & Electricity & Gas & Gasoline & Phone & Total \\
\hline Support & 75802218 & 172391072 & 138667124 & 115014338 & 17564247 & 415938999 \\
\hline Imaging & 15854059 & 36055649 & 29002274 & 2408227 & 3673568 & 86993778 \\
\hline Total & 494960853 & 1125261590 & 774991092 & 74800000 & 114799000 & 2584812535 \\
\hline Share & $19.2 \%$ & $43.5 \%$ & $30 \%$ & $2.9 \%$ & $4.4 \%$ & $100 \%$ \\
\hline
\end{tabular}

Table 3

Frequency and total relative value of services provided in imaging sector of Beheshti Hospital in 2015.

\begin{tabular}{cllllll}
\hline Indices & & $\begin{array}{l}\text { First } \\
\text { Quarter }\end{array}$ & $\begin{array}{l}\text { Second } \\
\text { Quarter }\end{array}$ & $\begin{array}{l}\text { Third } \\
\text { Quarter }\end{array}$ & $\begin{array}{l}\text { Fourth } \\
\text { Quarter }\end{array}$ & Total \\
\hline Number of & Outpatients & 5453 & 4380 & 4763 & 5008 & 20204 \\
Services & inpatients & 4979 & 5822 & 5210 & 5147 & 21158 \\
$\begin{array}{c}\text { Provided } \\
\text { Total relative }\end{array}$ & Sum & 10434 & 10802 & 9973 & 10155 & 41362 \\
value of & inpatients & 18161 & 20895 & 19473 & 18543 & 77071 \\
services & Sum & 46510 & 47815 & 46075 & 46371 & 186771 \\
(K) & & & & & & \\
& & & & & &
\end{tabular}

frequencies were related to the second (10802) and third (9973) quarters, respectively.

Total costs of imaging sector in 2015 amounted to $22,736,215,369$ IRR, with $94.9 \%$ of direct costs and $5.1 \%$ of indirect costs. Of the total costs of the imaging sector, there were $65.2 \%$ personnel, $8.3 \%$ consumed materials and supplies, $5.1 \%$ support units (public services, cleaning, etc.), 5.4\% depreciation of office, medical equipment and building repair, $15.5 \%$ contracts, and $0.4 \%$ energy conduits costs. The highest percentage of direct radiology services costs was related to human resources. The total cost of the support sector in Beheshti Hospital during the study period was 64,091,093,852 IRR. Regarding the imaging sector contribution, overhead costs were identified and added to the sector direct costs. Furthermore, depreciation and energy conduits costs formed a substantial portion of the direct radiology services costs.

In Table 4, the total cost of a relative value unit was estimated to be 128,518 IRR and the largest portion was associated with personnel costs amounted to 83836 IRR (65.2\%; see Table (4).

According to the approved tariff ( $\mathrm{K}=88000$ IRR) issued in 2015, the losses imposed on the hospital per $\mathrm{k}$ was equal to 40581 IRR. This represents the income deficit amounted to 7568 million IRR in the radiology department, compared to costs. The maximum financial loss resulting from the provision of imaging services amounted to 1937 million IRR for the second quarter and the minimum financial loss was equal to 1867 million IRR for the third quarter; see Table (5).

\section{Discussion}

A total of 41362 services were provided by imaging department of Beheshti Hospital within one year. There were 21158 and 20204 services provided for inpatients and outpatients, respectively. The highest frequency of service delivery $(n=10802)$ was observed in the second quarter and the lowest frequency $(\mathrm{n}=9973)$ was related to the third quarter.

Total relative value of imaging services provided in Beheshti Hospital for 4 quarters in 2015 shows that, of relative value of the services (K) equal to 186,771 , there were $109701(\mathrm{~K})$ and 77,071 relative value of the services $(\mathrm{K})$ provided for outpatients $(58.7 \%)$ and inpatients $(41.3 \%)$, respectively. The maximum $(n=47815,25.6 \%)$ and minimum ( $\mathrm{n}=46075,24.7 \%)$ numbers of services were provided in the second and third quarters, respectively. Of 152 types of services, 28 services formed $90 \%$ of total services provided.

The results of this study determined the amount of costs in administrative and support activity centers and its impact on total cost of services in imaging sector. Total cost calculated per $\mathrm{K}$ was equal to 128815 IRR, which was divided into direct and indirect costs. The direct costs were highly associated with the volume of performed activity and work. Costs in support centers (equal to $18 \%$ of the hospital total costs) had less effect on total cost of imaging services (1.5\%). The major cost component for the hospital were human resources and capital cost, it is supported by another studies. ${ }^{17}$ Costs were associated with personnel (65.2\%), consumed materials and supplies (8.3\%), support units including public services and cleaning (5.1\%), and depreciation of office and medical equipment and building repairs (5.4\%), contracts $(15.5 \%)$ and energy carriers $(0.4 \%)$. The findings are consistent with the results of a study conducted by Mahani et al., in $2011 .{ }^{18}$ Of the total costs of this sector, $7.57 \%, 1.32 \%, 0.32 \%$, and $14.96 \%$ of costs were reported for consumables and nutrition as well as water, electricity, phone and fuel and depreciation, respectively. The information provided by each center could greatly assist the hospital management to control and track expenses. Using the information provided by this system, activity-based budgeting can be performed for various sections of the hospital. ${ }^{19}$

\section{Conclusion}

The results of this study indicated that there are differences between the real price of radiology services and approved tariffs. The difference between a calculated relative value unit in imaging sector and tariffs approved in 2015 was significant. It is recommended that hospitals until the issuance of new tariffs to balance cost-income ratio have cost structure and financial reforms. Suggest until tariff amending, hospital commence to modify financial and personnel structures and repair its costs.

Table 4

Separated costs (IRR) for imaging department of Shagid Beheshti Hospital in 2015.

\begin{tabular}{|c|c|c|c|c|}
\hline Costs & Annual sum & frequency of the relative value of services provided & Costing (\%) & Cost per $\mathrm{K}$ \\
\hline Personnel costs & 14831574178 & 186.771 & $65.2 \%$ & 83836 \\
\hline Consumed materials and supplies & 1890280920 & 186.771 & $8.3 \%$ & 10685 \\
\hline Support (Public service and cleaning) & 1167024899 & 186.771 & $5.1 \%$ & 6597 \\
\hline Depreciation of office and medical equipment and building repair & 1231585256 & 186.771 & $5.4 \%$ & 6962 \\
\hline Other costs & 3516529253 & 186.771 & $15.5 \%$ & 19877 \\
\hline Energy conduits & 99220863 & 186.771 & $0.4 \%$ & 561 \\
\hline Sum & 22736215369 & 186.771 & $100 \%$ & 128518 \\
\hline
\end{tabular}


Table 5

Comparing the final cost (IRR) of services and revenue for imaging department divided by quarters.

\begin{tabular}{|c|c|c|c|c|c|}
\hline Indices & First Quarter & Second Quarter & Third Quarter & Fourth Quarter & Total \\
\hline Total relative value of services $(\mathrm{K})$ & 46815 & 47815 & 46075 & 46371 & 186771 \\
\hline Total cost of services & 5977421531 & 6145051285 & 5921504763 & 5959509849 & 24003487428 \\
\hline Revenues based on approved tariffs & 4092913792 & 4207694744 & 4054625960 & 4080649144 & 16435883640 \\
\hline Profit difference (loss) & 1884507739 & 1937356541 & 1866878803 & 1878860705 & 7567603788 \\
\hline
\end{tabular}

\section{Acknowledgments}

We would like to express our gratitude to the Vice Chancellor for Research and Technology in Hamadan University of Medical Sciences for their support in the implementation of this study in the form of MPH Thesis with No: 9504081671. We are also most grateful to the respected chair, manager and experts of Beheshti Hospital, especially employees in finance management and diagnostic imaging sectors for their valueless contribution.

\section{Appendix A. Supplementary data}

Supplementary data to this article can be found online at https:// doi.org/10.1016/j.cegh.2019.06.001.

\section{References}

1. Fazaeli AA, Fazaeli AA, Hamidi Y, Moeini B, Valinejadi A. Analysis of iranian household financial participation in the health system: decomposition of the concentration index approach. Koomesh. 2018:358-368.

2. Adam T, Evans DB. Determinants of variation in the cost of inpatient stays versus outpatient visits in hospitals: a multi-country analysis. Soc Sci Med. 2006;63(7):1700-1710

3. Duh R-R, Lin TW, Wang W-Y, Huang C-H. The design and implementation of ActivityBased Costing: a case study of a Taiwanese textile company. Int J Account Inf Manag. 2009;17(1):27-52.

4. Larsen J, Skjoldborg US. Comparing systems for costing hospital treatments: the case of stable angina pectoris. Health Policy. 2004;67(3):293-307.

5. Jericó MdC, Castilho V. Cost management: the implementation of the Activity-Based Costing method in sterile processing department. Rev Esc Enferm USP.
2010;44(3):745-752.

6. Chapko MK, Liu CF, Perkins M, Li YF, Fortney JC, Maciejewski ML. Equivalence of two healthcare costing methods: bottom-up and top-down. Health Econ. 2009;18(10):1188-1201.

7. Yereli AN. Activity-based costing and its application in a Turkish university hospital. AORN J. 2009;89(3):573-591.

8. Cinquini L, Miolo Vitali P, Pitzalis A, Campanale C. Process view and cost management of a new surgery technique in hospital. Bus Process Manag $J$. 2009;15(6):895-919.

9. Baratti D, Scivales A, Balestra MR, et al. Cost analysis of the combined procedure of cytoreductive surgery and hyperthermic intraperitoneal chemotherapy (HIPEC). Eur J Surg Oncol. 2010;36(5):463-469.

10. Fazaeli AA, Seyedin H, Moghaddam AV, et al. Health care expenditure and GDP in oil exporting countries: evidence from OPEC data, 1995-2012. Glob J Health Sci. 2015;7(5):260.

11. Kazemi Z, Zadeh HA. Activity based costing: a practical model for cost price calculation in hospitals. Ind J Sci Technol. 2015;8(27).

12. Lawson RA. The use of activity based costing in the healthcare industry: 1994 vs. 2004. Res Healthc Financ Manag. 2005;10(1):77.

13. Olukoga A. Unit costs on inpatient days in district hospitals in South Africa. Singap Med J. 2007;48(2):143.

14. Rajabi A, Dabiri A. Applying activity based costing (ABC) method to calculate cost price in hospital and remedy services. Iran J Public Health. 2012;41(4):100.

15. RAJABI A. The Role of Activity Based Costing ( $A B C$ ) System in Governmental Hospital Services in Iran. 2008; 2008.

16. HADIAN M, MOHAMMADZADEH A, IMANI A, Golestani M. Analysis and Unit Cost Estimation of Services Using "Step-Down Method" in Fatemieh Hospital of Semnan University of Medical Sciences-2006. Iran 2009; 2009.

17. Chatterjee S, Levin C, Laxminarayan R. Unit cost of medical services at different hospitals in India. PLoS One. 2013;8(7):e69728.

18. Mahani A, Barani M, Bahrami M, Goudarzi G. Cost price estimation of radiology services in shafa hospital, kerman. J Health School. 2010;10:50-61.

19. Aldogan M, Austill AD, Kocakülâh MC. The excellence of activity-based costing in cost calculation: case study of a private hospital in Turkey. J Health Care Financ. 2014;41(1). 